\title{
Analysis of Meteorological Conditions for a Sea Fog Process in 2016
}

\author{
Xiaomeng Shi1 ${ }^{12 *}$, Xueying Liư3, Yu Gu², Qian Wang4 \\ ${ }^{1}$ Qingdao Engineering Technology Research Center for Meteorological Disaster Pretention, Qingdao Meteorological Bureau, \\ Qingdao, China \\ ${ }^{2}$ Qingdao Meteorological Observatory, Qingdao Meteorological Bureau, Qingdao, China \\ ${ }^{3}$ Jiaozhou Meteorological Bureau, Qingdao, China \\ ${ }^{4}$ Huangdao District Meteorological Bureau, Qingdao, China \\ Email: *shi198710@126.com
}

How to cite this paper: Shi, X.M., Liu, X.Y., Gu, Y. and Wang, Q. (2021) Analysis of Meteorological Conditions for a Sea Fog Process in 2016. Atmospheric and Climate Sciences, 11, 419-425.

https://doi.org/10.4236/acs.2021.113024

Received: April 5, 2021

Accepted: May 28, 2021

Published: May 31, 2021

Copyright (c) 2021 by author(s) and Scientific Research Publishing Inc. This work is licensed under the Creative Commons Attribution International License (CC BY 4.0).

http://creativecommons.org/licenses/by/4.0/

\begin{abstract}
The visibility characteristics and meteorological conditions of a sea fog process on $27^{\text {th }}$ February, 2016 are analyzed and the heavy fog process is simulated by the Weather Research and Forecasting (WRF) model in this paper. The forecast results show that the visibility in Qingdao coastal area is light fog on the night of the $26^{\text {th }}$. In the WRF simulation, it can be observed from the sea-level pressure that the wind direction of Qingdao and the coastal area turned southerly with the eastward movement of the low pressure system on surface from 1200 UTC to 1800 UTC on the $26^{\text {th }}$. A large amount of water vapor brought by easterly and southerly wind provides sufficient water vapor conditions for the formation and development of the sea fog. At $975 \mathrm{hPa}$, there is a strong warm tongue over Shandong Peninsula at 0600 UTC on the $26^{\text {th }}$, while the offshore is affected by the cold tongue, where the horizontal temperature gradient is large and there is a strong baroclinicity. At $850 \mathrm{hPa}$, there is a weak warm ridge over Qingdao at 1200 UTC on the $26^{\text {th }}$, which means that it is an inversion layer, which is conducive to the maintenance of fog.
\end{abstract}

\section{Keywords}

Qingdao Offshore, Heavy Fog, WRF, Satellite Remote Sensing, Dual-Channel

\section{Introduction}

Sea fog is a weather phenomenon that occurs in the near land or water surface layer. After the occurrence of sea fog, the horizontal visibility of the sea surface is less than $1000 \mathrm{~m}$, sometimes even less than $50 \mathrm{~m}$, which brings great danger to the safety of ships sailing and is called "silent killer", so sea fog is known as the 
"silent killer" on the sea. According to the incomplete statistics of Qingdao Maritime Safety Administration, nearly 50\% of ship collisions or grounding accidents are related to sea fog.

The systematic research on sea fog in China can be traced back to the 1960s, professor Wang Binhua accumulated more than 40 years of research results and published the world's first monograph on sea fog, called "sea fog".

There are five relatively foggy areas along the coast of China from south to North: the Leizhou Peninsula and the Qiongzhou Strait, Fujian coast area, Zhoushan Archipelago, sea area near Qingdao-ChaoLian Island and sea area near Chengshantou, the Yellow Sea includes two of them. In recent years, the research on the distribution characteristics and formation conditions of sea fog over the Yellow Sea has been paid attention by scholars.

The maximum frequency of sea fog is from 4 am to 10 am every day, followed by $20 \mathrm{pm}$ to $3 \mathrm{am}$ the next day. Gao et al. used a mesoscale model to simulate a sea fog case [1]. With the enrichment of satellite data and the development of remote sensing technology, many scholars began to use remote sensing technology to identify and forecast fog over recent years. Hunt found that the emissivity of opaque clouds (such as fog, low cloud and ice cloud) is significantly different in the mid-infrared band and long wave infrared band [2]. On this basis, Eyer et al. used AVHRR/NOAA brightness temperature difference between mid-infrared band and long wave infrared band to identify fog/low cloud at night [3]. After that, Turner et al., Bendix et al., Reudenbach and Bendix continuously tried and applied, and formed a method called "dual-channel" which is widely used in meteorological operation to identify fog/low cloud at night [4] [5] [6]. Then, Zhang and Yi, Yi et al. used Dynamic Threshold to distinguish sea fog and low clouds [7] [8] [9].

With the rapid development of numerical forecast technology, by adding fog diagnosis algorithm in the post-processing module of numerical model, China has initially established the Sea Fog Numerical Prediction System for the Yellow Sea, Bohai Sea and coastal region in the East China, which provides technical support for sea fog forecast in coastal areas. This paper will analyze the meteorological conditions of the sea fog process which occurred on February $27^{\text {th }}, 2016$ through the analysis and numerical simulation. The purpose of this paper is to enrich the research cases of sea fog along the coast of Qingdao and improve the operational forecasting ability of sea fog

\section{Data and Methods}

The Weather Research and Forecasting (WRF) model is used to examine the physical processes involved in the fog event. The center of domains is at $\left(116^{\circ} \mathrm{E}\right.$, $\left.39^{\circ} \mathrm{N}\right)$. The entire grid system has 46 vertical layers in $\eta$ coordinates. The main physical options of the models are shown in Table 1 . The time step is $120 \mathrm{~s}$. The reanalysis data from FNL and SST product from EAR-GOOS are used as the initial and boundary conditions. 
Routine weather data (eight times daily) and GPS soundings (two times daily) are provided by Qingdao Meteorological Administration. The visibility is obtained from an automatic weather station (ATWS) in Qingdao with the sampling interval in 10 minutes.

\section{Observations}

Figure 1 shows the visibility from 2000 LST $26^{\text {th }}$ to 0800 LST $27^{\text {th }}$, as shown in this Figure, The visibility dropped significantly form 2000 LST to 2200 LST $26^{\text {th }}$ February. Especially, the visibility reduced most at the Daqiao4 station and dropped below $1000 \mathrm{~m}$ at other stations successively, which means a heavy fog occurred. In some periods, the visibility dropped below $100 \mathrm{~m}$.

\section{Weather Situation Analysis}

From the sea level pressure field (Figure 2), it can be seen that from 1200 UTC on the $25^{\text {th }}$ to 0000 UTC on the $26^{\text {th }}$, the Qingdao area was mainly affected by the inverted trough on the ground, and the wind direction changed from southerly to easterly. At 0600 UTC on the $26^{\text {th }}$, Qingdao was located in the northwest of the low pressure. The wind direction of the land on the west side of Qingdao is westerly, and the wind direction of the ocean on the east side of Qingdao is easterly.

Table 1. Specification of WRF modeling.

\begin{tabular}{ccc}
\hline & Domain 1 & Domain 2 \\
\hline Grid spacing $(\mathrm{km})$ & 30 & 10 \\
Timesteps $(\mathrm{s})$ & 120 & 60 \\
IC/BC & FNL and EAR-GOOS & Domain 1 \\
Convection & Betts-Miller-Janjic & \\
Longwave Radiation & RRTMG & \\
Shortwave Radiation & RRTMG & \\
PBL & MYNN2 & \\
Microphysics & Eta(Ferrier) \\
Surface & Noah & \\
\hline
\end{tabular}

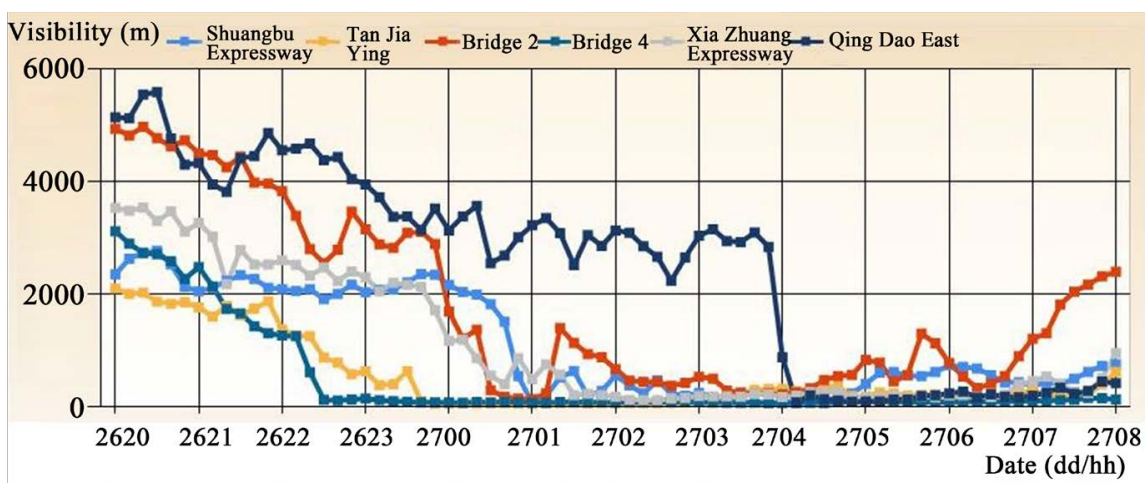

Figure 1. The time series of visibility from 2000 LST $26^{\text {th }}$ to 0800 LST $27^{\text {th }}$ FEB 2016. 

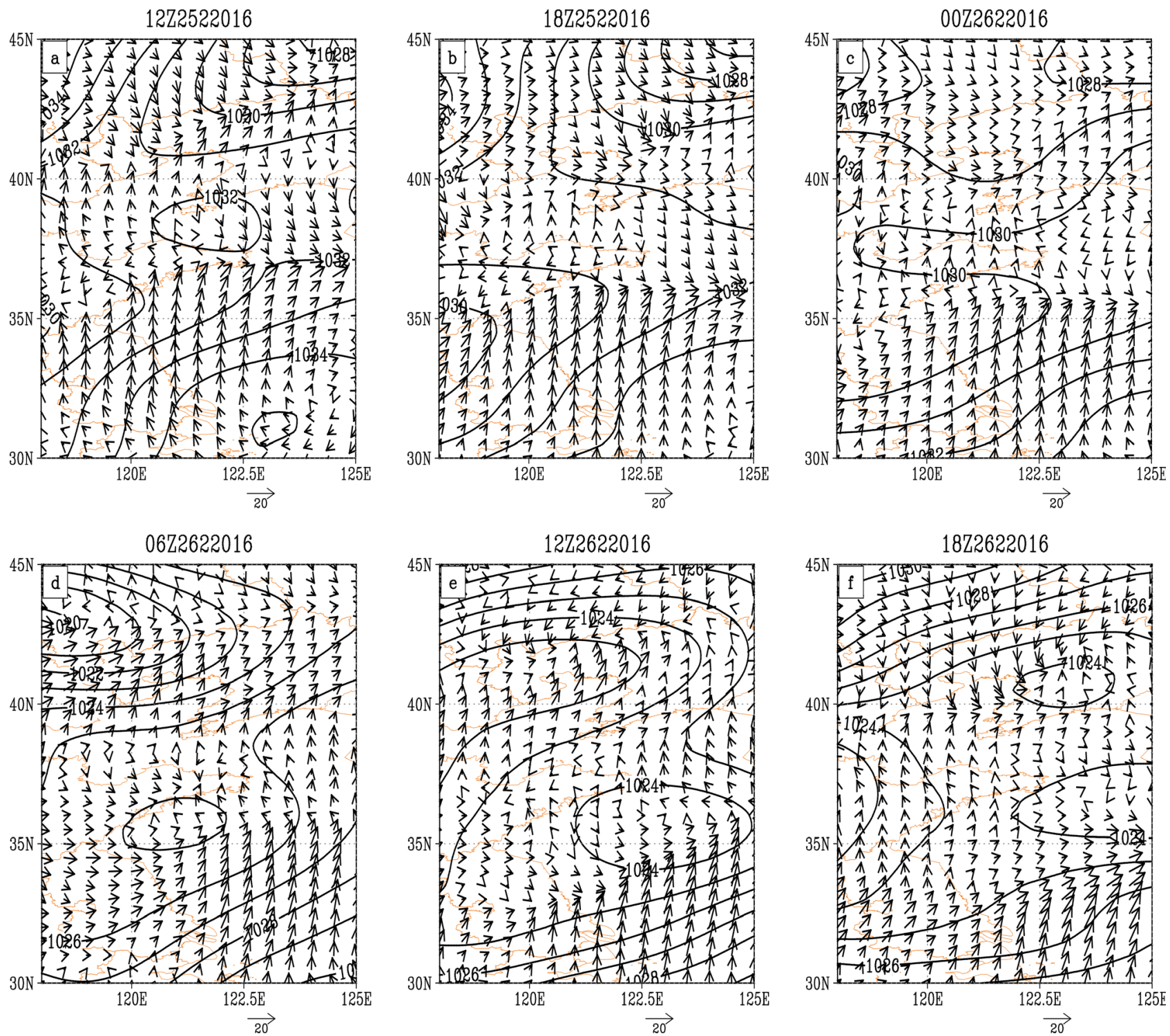

Figure 2. Sea level pressure field (solid line, $1 \mathrm{hPa}$ interval) and $1000 \mathrm{hPa}$ horizontal wind field (vector) (The red lines represent the land topography).

From 1200 UTC to 1800 UTC on the $26^{\text {th }}$, as the ground low pressure system moved eastward, the wind direction in Qingdao and adjacent sea areas turned to south. The easterly wind and the southerly wind carry a large amount of water vapor, and the water vapor conditions for the formation and development of sea fog are sufficient.

It can be seen from Figure 3 that, except for 0000 UTC on the $26^{\text {th }}$, the isotherms of Qingdao and adjacent sea areas are relatively dense. From 1200 UTC on the $25^{\text {th }}$ to 1800 UTC on the $26^{\text {th }}$, the area has been affected by warm advection and the warm advection is strong except for 1200 UTC on the $26^{\text {th }}$. At 1200 and 1800 UTC on the $25^{\text {th }}, 1200$ UTC on the $26^{\text {th }}$, there was a weak warm tongue in Qingdao offshore. At 0600 UTC on the $26^{\text {th }}$, there was a strong warm tongue over the Shandong Peninsula, while the coastal waters were affected by the cold 

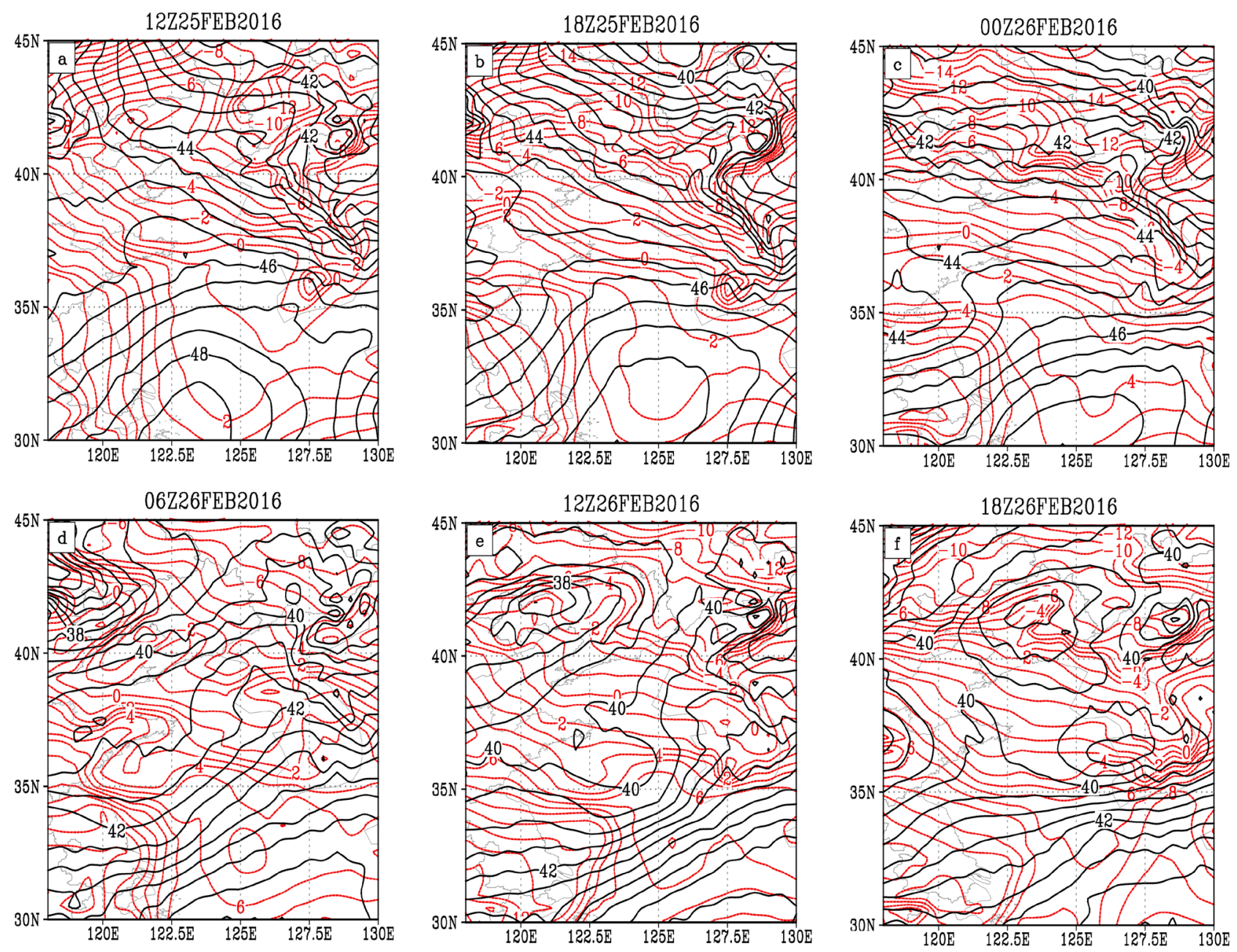

Figure 3. $975 \mathrm{hPa}$ weather chart. The black line is the geopotential height (interval $5 \mathrm{gpm}$ ), the red line is the temperature (interval $\left.1^{\circ} \mathrm{C}\right)$.

tongue, where the horizontal temperature gradient was large, and there was strong baroclinicity.

Except for 0600 UTC on the $26^{\text {th }}$, there has been warm advection over Qingdao (picture omitted). From 1200 UTC on the $25^{\text {th }}$ to 0000 UTC on the $26^{\text {th }}$, the warm tongue is located in the Yellow Sea and is constantly moving eastward. A warm tongue was formed on the land west of Qingdao at 0000 UTC on the $26^{\text {th }}$, and a strong warm tongue was present over the Shandong Peninsula at 0600 UTC on the $26^{\text {th }}$, while a cold tongue was seen offshore. The formation of this inversion layer was a favorable condition for the development of fog.

It can be seen that the isotherms of Qingdao and adjacent sea areas are relatively dense. There has always been a warm advection over Qingdao. This provides favorable conditions for the development of sea fog to form an inversion layer. There are weak warm ridges over Qingdao from 12 UTC on the $25^{\text {th }}$ to 00 UTC on the $26^{\text {th }}$ and 12 UTC on the $26^{\text {th }}$, which means that there is still a weak temperature inversion here, which is conducive to the maintenance of fog. This feature still exists at levels below $850 \mathrm{hPa}$ and the warm ridge is more pronounced 

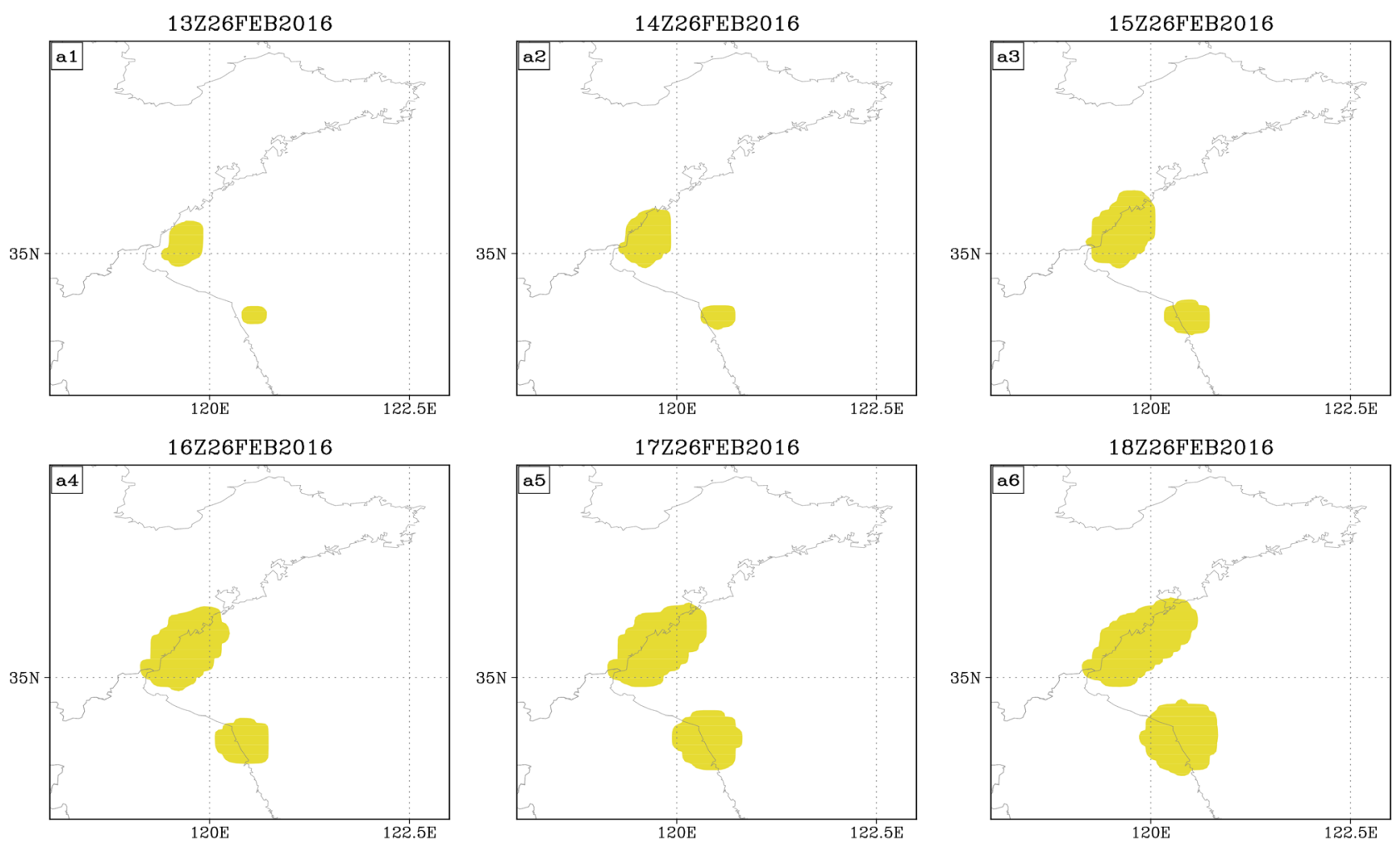

Figure 4. Cloud-water mixing ratio distribution map. The filling is greater than $0.016 \mathrm{~g} / \mathrm{kg}$.

than $850 \mathrm{hPa}$. The schematic diagram of cloud-water mixing ratio (Figure 4) shows that the foggy area extends from southwest to northeast.

\section{Summary}

It can be seen from the sea level pressure field that from 1200 UTC to 1800 UTC on the $26^{\text {th }}$, with the eastward movement of the surface low pressure system, the wind direction of Qingdao and its adjacent coastal areas turned southerly. The easterly and southerly winds bring a lot of water vapor, which provides sufficient water vapor conditions for the formation and development of sea fog.

\section{Discussion}

At $975 \mathrm{hPa}$, there is a strong warm tongue over Shandong Peninsula at 0600 UTC on the $26^{\text {th }}$, while the offshore is affected by the cold tongue, where the horizontal temperature gradient is large and there is a strong baroclinicity. At 850 $\mathrm{hPa}$, there is a weak warm ridge over Qingdao at $1200 \mathrm{UTC}$ on the $26^{\text {th }}$, which means that it is an inversion layer, which is conducive to the maintenance of fog.

\section{Acknowledgements}

This work was funded by The Project of Shandong Meteorological Bureau (grant number 2017sdqxm11/SDYBY2018-06), The Marine Meteorology Research and Development program of Qingdao Meteorological Bureau (grant number 2019qdqxz02). 


\section{Conflicts of Interest}

The authors declare no conflicts of interest regarding the publication of this paper.

\section{References}

[1] Gao, S.H., Wu, W., Zhu, L., et al. (2009) Detection of Nighttime Sea Fog/Stratus over the Huanghai Sea Using MTSAT-1Rdata. Acta Oceanol Sincia, 28, 23-35.

[2] Hunt, G.E. (1973) Radiative Properties of Terrestrial Clouds at Visible and Infra-Red Thermal Window Wavelengths. Quarterly Journal of the Royal Meteorological Society, 99, 346-369. https://doi.org/10.1002/qj.49709942013

[3] Eyre, J.R., Brownscombe, J.L. and Allam, R.J. (1984) Detection of Fog at Night Using Advanced Very High Resolution Radiometer (AVHRR) Imagery. Meteorology Magazine, 113, 266-271.

[4] Turner, J., Allama, R.J. and Maine, D.R. (1986) A Case Study of the Detection of Fog at Night Using Channels 3 and 4 on the Advanced Very High Resolution Radiometer (AVHRR). Meteorology Magazine, 115, 285-297.

[5] Bendix, J. (2002) A Satellite-Based Climatology of Fog and Low-Level Stratus in Germany and Adjacent Areas. Atmosphere Research, 64, 3-18. https://doi.org/10.1016/S0169-8095(02)00075-3

[6] Reudenbach, C.H. and Bendix, J. (1998) Experiments with a Straightforward Model for the Spatial Forecast of Fog/Low Stratus Clearance Based on Multi-Source Data. Meteorological Applications, 5, 205-216. https://doi.org/10.1017/S1350482798000814

[7] Zhang, S.P. and Yi, L. (2013) A Comprehensive Dynamic Threshold Algorithm for Daytime Sea Fog Retrieval over the Chinese Adjacent Seas. Pure and Applied Geophysics, 170, 1931-1944. https://doi.org/10.1007/s00024-013-0641-6

[8] Yi, L., Zhang, S.P., Thies, B., Shi, X.M., Trachte, K. and Bendix, J. (2015) Spatio-Temporal Detection of Fog and Low Stratus Top Heights over the Yellow Sea with Geostationary Satellite Data as a Precondition for Ground Fog Detection: A feasibility Study. Atmospheric Research, 151, 212-223. https://doi.org/10.1016/j.atmosres.2014.03.020

[9] Yi, L., Thies, B., Zhang, S.P., Shi, X.M. and Bendix, J. (2016) Optical Thickness and Effective Radius Retrievals of Low Stratus and Fog from MTSAT Daytime Data as a Prerequisite for Yellow Sea fog Detection. Remote Sensing, 8, 8. https://doi.org/10.3390/rs8010008 